\title{
DIFERENCIAS PRODUCTIVAS ESTRUCTURALES ENTRE EL CENTRO Y LA PERIFERIA: MAGALLANES Y ARICA VERSUS EL PROMEDIO NACIONAL
}

\author{
PATRICIO AROCA* \& SERGIO SOZA-AMIGO**
}

\section{RESUMEN}

La concentración en el centro del país ha alcanzado límites que podrían estar afectando negativamente el crecimiento de la nación, sin embargo la falta de información, no permite una afirmación definitiva al respecto. Este trabajo pretende contribuir a esta discusión, contrastando la hipótesis de que al menos las dos regiones extremas del país; Magallanes y Arica, tienen estructuras productivas significativamente distintas a la estructura nacional, lo que demandaría políticas complementarias específicas para estas regiones, para conseguir metas similares a los buscadas por la política nacional.

Utilizando matrices de insumo-producto para ambas regiones, se encuentra que las estructuras productivas de la región de Magallanes y de Arica, presentan grados de desarrollo, medidos a través de encadenamientos productivos y niveles de producción, considerablemente inferiores al de la economía nacional. Estos resultados refuerzan la idea que aquellas políticas basadas en la estructura económica nacional, podría no proveer los resultados buscados a las zonas extremas, generando unas necesidades por políticas específicas y complementarias a las macroeconómicas globales que se aplican en Chile. ${ }^{1}$

PALABRAS CLAVE: regiones extremas, análisis estructural, encadenamientos, campos de influencia.

Clasificación JEL: C49, C67, D57, F02, R11.

\section{PRODUCTIVE STRUCTURE DIFFERENTIAL BETWEEN THE CORE AND THE PERIPHERY: MAGALLANES AND ARICA VERSUS THE COUNTRY}

\footnotetext{
ABSTRACT

The concentration around the core of country has reached a level that might be hurting the growth of the economy. However, there is not enough information that allow to make a definitive statement about it most peripheral regions: Magallanes and Arica, have productive structures significantly different from national one, which call for complementary specific policies for these regions, to get similar targets pursue by the national and spatially blind policy.

* Escuela de Negocios, Universidad Adolfo Ibáñez, Viña del Mar, Chile, e-mail: patricio.aroca@uai.cl.

***Facultad de Ciencias Económicas y Jurídicas, Universidad de Magallanes, Punta Arenas, Chile, e-mail: sergio.soza@umag.cl.

1 Se reconocen y agradecen los financiamientos entregados por parte del Ministerio de Economía, Fomento y Turismo, Proyecto NS 100046, de la Iniciativa Científica Milenio y a su Red Insumo- Producto y, a FONDECYT, por medio de los proyectos: "El Efecto de la Concentración Espacial en el Crecimiento de la Economía Chilena", Número: 1120699 y "Entre el Conflicto y el Aislamiento: Desarrollo, Gobernabilidad y Seguridad en las Zonas Fronterizas del Norte y el Sur de Chile a Comienzos del Siglo XXI", Número: 1120405.
} 
The analysis of Input-Output matrices, their linkages and production levels, for Magallanes and Arica, shown that the productive structure of the peripheral regions belong to a less developed economy compared with the national one. This supports the idea that those policies based on the national economic structure do not have the expect impact on the peripheral regions. Therefore, there is a call for specific and complementary regional policy focus on these regions that complement the national macroeconomic policies.

KEY WORDS: peripheral regions, structural analysis, linkage, fields of influence.

Classification JEL: C49, C67, D57, F02, R11.

\section{INTRODUCCIÓN}

El diseño de la política económica nacional, se basa fundamentalmente en indicadores macroeconómicos, que ignoran la heterogeneidad del impacto de las mismas sobre el territorio. Por ejemplo, una política monetaria contractiva vía incremento en la tasa de interés (reducción de la oferta monetaria), tendrá un impacto nacional y será el esperado sobre aquellas regiones que presentan signos de calentamiento ${ }^{2}$, mientras que para las otras regiones que aún tienen espacio para crecer ésta política implicará una pérdida de oportunidades de crecimiento (Sarrias \& Aroca, 2012).

En este contexto, es importante conocer que regiones tienen estructuras productivas similares a la del país y especialmente, cuáles difieren significativamente ya que éstas requerirían de políticas regionales complementarias, cada vez que se aplica una política macroeconómica global (Aroca \& Atienza, 2011 y 2008 y Atienza \& Aroca, 2012).

En este trabajo, se plantea la hipótesis de que al menos las dos regiones extremas del país; Magallanes y Arica, tienen estructuras productivas significativamente distintas a la estructura nacional, lo que sugiere políticas complementarias específicas para estas regiones.

Utilizando matrices de insumo-producto para ambas regiones, se comparan con la matriz nacional del año 2008, y se encuentra que las estructuras productivas de la región de Magallanes y de Arica, presentan grados de desarrollo, medidos a través de encadenamientos productivos y niveles de producción, considerablemente inferiores al de la economía nacional. Esto implica que las políticas

2 Una economía da muestras de "calentamiento", cuando su capacidad productiva no ésta en consonanacia con el ritmo decreciente de su demanda agregada. macroeconómicas formuladas en base a la estructura productiva nacional, no tendrán los efectos esperados en éstas regiones.

Adicional a la estructura económica en las regiones extremas,surge otro proceso que atenta con el desarrollo de las mismas. El bajo nivel de desarrollo de las regiones, también se manifiesta en una escasa provisión de bienes públicos de calidad, lo que motiva a que una proporción importe de trabajadores que laboran en estas regiones resida en alguna otra que ofrece mejores estándares de calidad de vida.

Brandao (1973) al afirmar que la migración es parte de, y también factor de desarrollo, y no sólo resultado de éste, vincula la migración y conmutación al desarrollo, estableciendo de éste modo, un segundo aspecto a revisar, el comportamiento migratorio y de conmutantes; así, sí los Bienes Públicos y las estructuras económicas son las adecuadas, el resultado será un mayor desarrollo. Bajo éste último contexto, no se debe olvidar que el desarrollo trae asociado etapas y estructuras (Hewings et al., 1998 y 1988; West \& Brown, 2003, Hidalgo et al., 2007 e Hidalgo \& Hausmann, 2008 y 2009), especializaciones y umbrales (Imbs \& Wacziarg, 2003), tipos de procesos tecnológicos (Leontief, 1963) y, estructuras que acusan ciertas características intrínsecas al tipo de economía, geografía y referencia temporal, las denominadas Estructuras Económicas Fundamentales (Thakur, 2011, 2010 y 2008). Por tanto, desde la perspectiva estructural, es importante identificar cuán semejantes o divergentes se es con respecto a un patrón de referencia que se supone da pies a un mayor dinamismo y ventajas en variados aspectos; actividades más dinámicas y de rápido crecimiento, contribuyen más en términos de producción y generación de empleo, lo que implica un mayor aporte al desarrollo.

Los resultados, sugieren la implementación de 
políticas orientadas a incrementar los encadenamientos productivos en la región de Magallanes y a definir y/o "potenciar" una vocación productiva para la región de Arica y Parinacota. Los sectores asociados a la actividad turística, aún cuando no son tratados en forma explícita (27 (construcción); 28 (comercio); 29 (hostelería y restaurantes); transportes en general (30 y 31) y; 33 (comunicaciones); muestran un potencial de desarrollo que podrían ayudar a la definición de Arica y Parinacota y a los incrementos de los encadenamientos en Magallanes.

El trabajo que se presenta ésta organizado en las siguientes secciones. En la primera se explica la metodología que se utilizará; en la segunda parte, se discute sobre los resultados obtenidos, se sugieren posibles explicaciones sobre los mismos y se entregan algunas políticas para mejorar lo observado; finalmente, se presentan las conclusiones.

\section{METODOLOGÍA}

Para estimar los distintos efectos y semejanzas estructurales se utilizan las Matrices Insumo-Producto de Chile $e^{3}$ y de las comunas de Punta Arenas y Arica ${ }^{4}$, las cuales reflejan las estructuras productivas sectoriales del país y de las regiones a estudiar. La matriz de la comuna de Punta Arenas como la de Arica, son utilizadas como aproximaciones de sus respectivas regiones, dado que ellas representan en términos de PIB en promedio más del $90 \%$ de la actividad regional que se genera donde las mismas están ubicadas.

Para establecer las diferencias estructurales, se realizarán las siguientes comparaciones entre las respectivas Matrices Insumo- Producto:

\section{- Chile- Arica \\ - $\quad$ Chile- Punta Arenas \\ - Punta Arenas- Arica}

Adicionalmente utilizaremos la técnica que se denomina Matriz de Multiplicadores de ProducciónPonderados (MPM), para mostrar los efectos de cada actividad sobre el sistema económico; y la de los Campos de Influencia (CdI), para observar cómo

3 Elaborada por el Banco Central de Chile y fechada para el año 2008 (patrón de comparación).

4 Ambas datadas para el año 2007 y obtenidas en forma indirecta mediante la técnica RAS, basados en las Matrices Regionales publicadas por MIDEPLAN en 2002 (Aproximación a las Economías Regionales. Santiago, Chile, Ministerio de Planificación, 2005, p. 211). se relacionan o vinculan en términos de sensibilidad las actividades dentro de cada economía. Con tales técnicas se obtendrán imágenes de las regiones respecto al contexto nacional, de ésta forma se revisarán los espacios que le quedan a cada economía menor para seguir creciendo y se acentuarán las diferencias que hacen que las mismas se retrasen o pierdan oportunidades de desarrollo, producto de la estructura económica global en las que están insertas.

El método MPM, se basa en el concepto clásico de "industria clave", acuñado por Rasmussen (1956) y ampliado por Hirschman (1958). Según sus propios autores (Sonis \& Hewings, 2009: 85-90), éste nuevo planteamiento al basarse en la matriz inversa de Leontief ponderada por su intensidad, tiene la fortaleza de brindar la posibilidad de observar simultáneamente por medio de un gráfico tres aspectos de las estructuras; esto es, en los ejes inferiores se presenta el "orden jerárquico" de cada etapa productiva, basada en los efectos que la misma ejerce sobre el resto del sistema económico (encadenamientos hacia delante (BL) y atrás (FL), respectivamente $e^{5}$ ) y, en vertical sus efectos multiplicadores en un sentido de la magnitud de los mismos.

Con el fin de explicar lo anterior, consideramos la Fig. 1, ella muestra la MPM de las cinco actividades mas importantes para la economía chilena del año 2008, como se puede observar en la parte baja, se representa los encadenamientos jerarquizados en base al impacto del Multiplicador que presentan las mismas.

En términos de análisis la Fig. 1, indica entre otros los siguientes aspectos: primero; una economía homogénea en términos de impacto, ya que los mismos van disminuyendo de forma relativamente gradual y homogénea (tanto para los BL como los FL); segundo, que la relación más importante en términos de requerimientos y efectos multiplicadores entre actividades es la que presentan los servicios

5 Un encadenamiento, hacia atrás (BL) o delante (FL), representa la capacidad que tiene una actividad de arrastrar o empujar al resto del sistema económico, en la medida que la misma se desarrolla; por tanto, una actividad será importante bajo éste contexto, cuando más dispersos sean sus efectos y simultáneamente más dinamice al sistema económico. Basado en lo anterior se pueden encontrar 4 tipos de actividades; claves (BL y FL sobre el promedio), impulsoras (BL sobre el promedio y FL bajo éste), base (BL bajo el promedio y FL sobre el mismo) e islas (BL y FL bajo el promedio). 


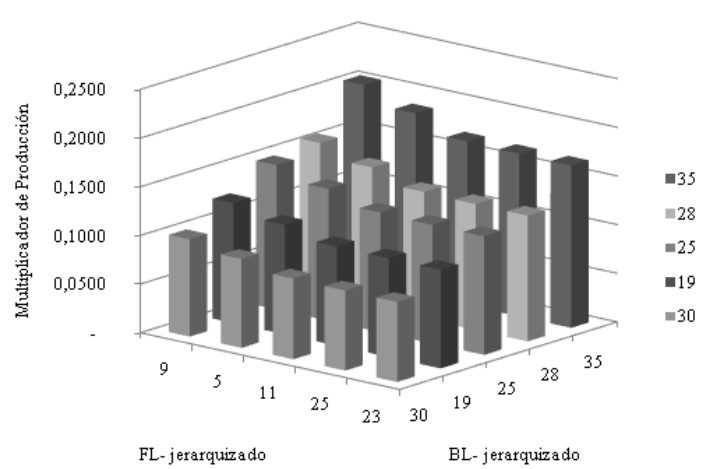

Fig. 1 MPM de las cinco actividades más importantes para la economía chilena del año 2008.

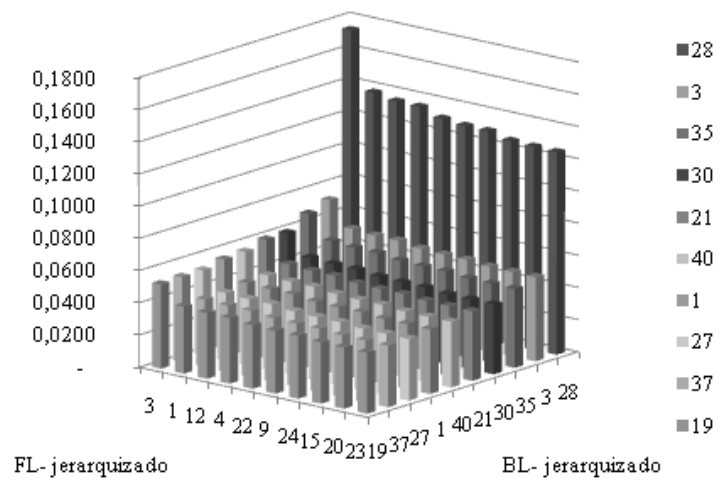

Fig. 3MPM con las 10 actividades principales por economía (en negrilla las coincidencias respecto a Chile). Arica 2007.

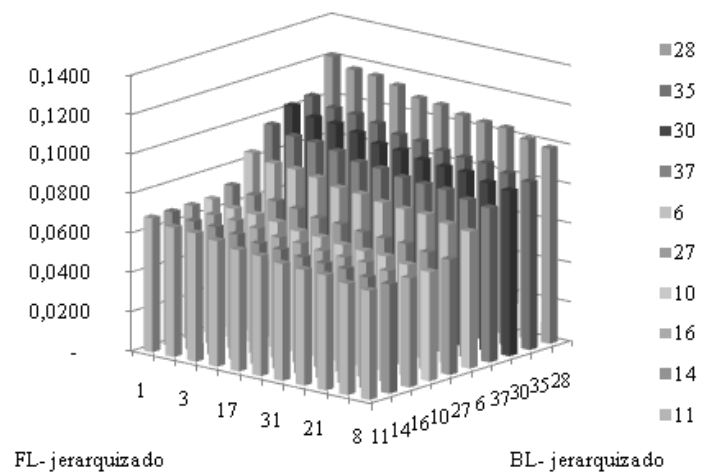

Fig. 5 Punta Arenas 2007 (sin graficar actividad 19).

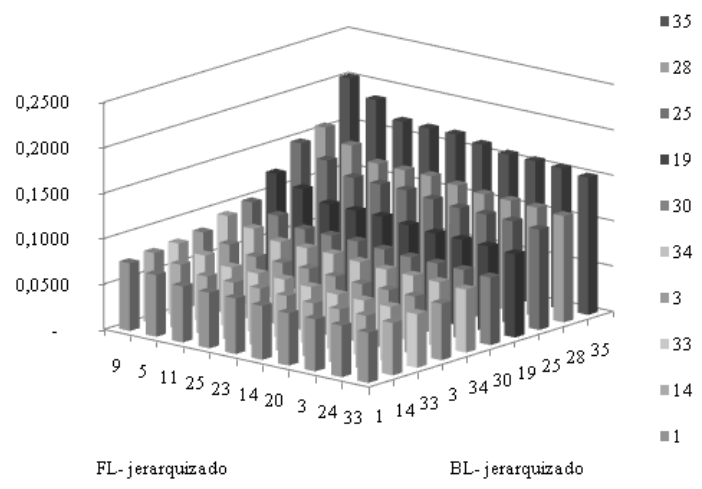

Fig. 2 MPM- con las 10 actividades principales para Chile.

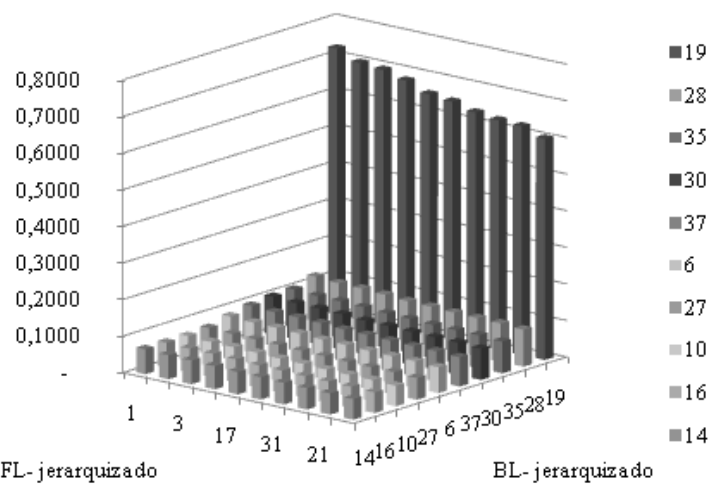

Fig.4 MPM con las 10 actividades principales por economía (en negrilla las coincidencias respecto a Chile). Punta Arenas 2007.

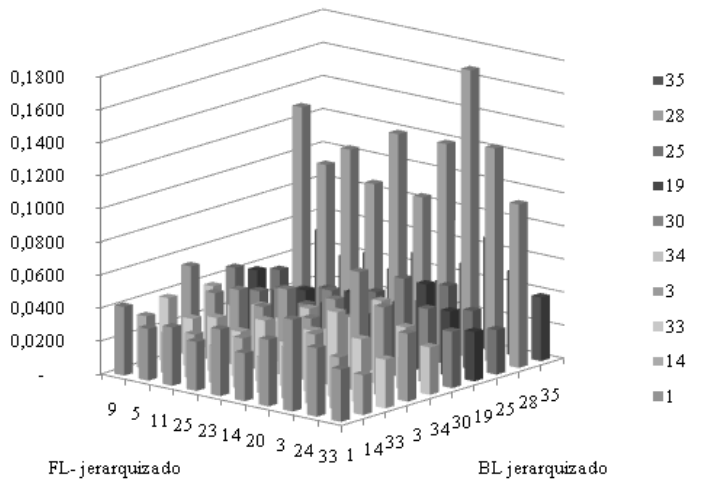

Fig. 6 MPM para Arica con las 10 principales actividades en base a la estructura de Chile-08. 


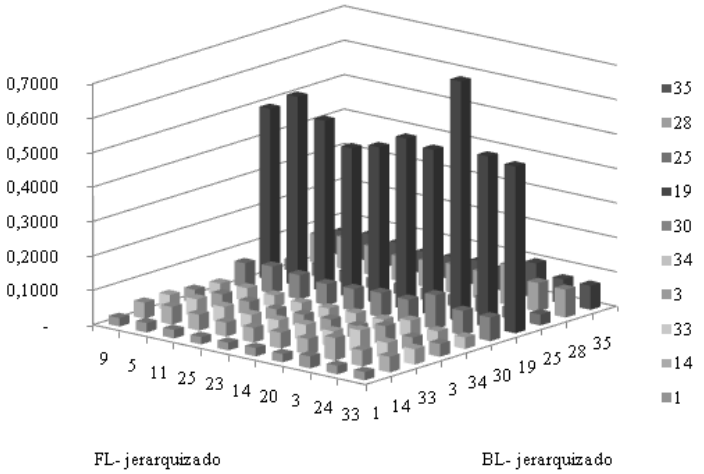

Fig. 7 MPM para Punta Arenas con las 10 principales actividades en base a la estructura de Chile-08.

empresariales (35) y conservas de frutas y vegetales (9); tercero, que el impacto que genera la actividad 35 , en términos de los requerimientos que demanda para su funcionamiento es mayor y más homogéneo que el impacto que tiene en términos de oferta la actividad 9, los que de acuerdo a la figura presentan una baja constante pero más pronunciada que los anteriores y; cuarto, por cada unidad de incremento del consumo gestado en la demanda final de la actividad 35 , se observa un incremento de la producción de aproximadamente 0,20 unidades dada la relación que existe entre ésta y la actividad 9.

Siguiendo metodología planteada por Sonis y Hewings, se cree que la misma se puede complementar aún más si ella se focaliza en lo que verdaderamente influye en el desarrollo (efectos indirectos; Rasmussen, 1956: 134). Así, se retoman dos ideas, la de encadenamientos que se obtienen a partir de los efectos indirectos totales ${ }^{6}$ y la de encadenamientos que resultan como efecto indirectos ${ }^{7}$ hacia otras industrias, los que tienen la particularidad de develar qué actividades son los que realmente influyen sobre el resto del sistema económico. Una vez obtenidas estas nuevas matrices, se procede a ponderar siguiendo la propuesta de Sonis \& Hewings.

El segundo método destaca por recoger la idea de elasticidad formulada por Sebald (1974) y por considerar la totalidad del problema que se estudia

6 Los que son obtenidos de la diferencia entre la matriz inversa de Leontief y una matriz con diagonal principal unitaria.

7 Estos se obtienen de la diferencia entre la matriz inversa de Leontief y la diagonal principal de la misma. Ello en la práctica, significa excluir del sistema económico, los propios impactos que genera para sí mismo la industria que se estudia, es decir, su autoconsumo.

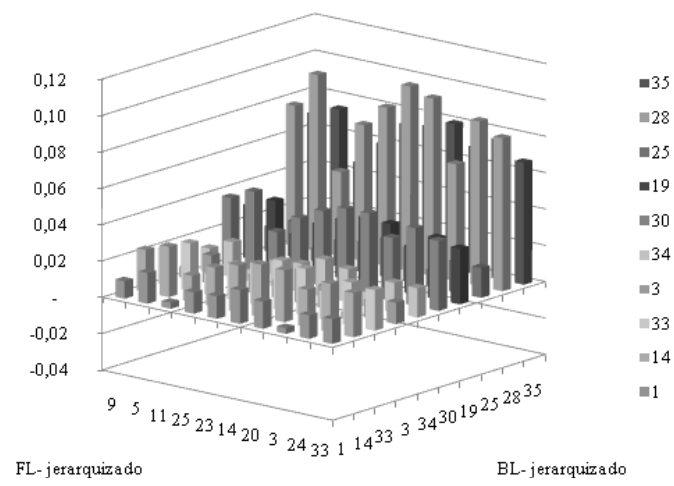

Fig.8 Diferencia Neta en MPM entre Arica y Punta Arenas, tomando la estructura de Chile como base.

al hacer uso de la ecuación original desarrollada por Schintke \& Stäglin y no una parcelación de ésta última (ie: las propuestas de Schnabl, 1994 o la de Holub \& Schnablde, 1994), en tal sentido, para obtener los CdI se utiliza el procedimiento empleado por Soza-Amigo, 2008 y 2011, el cual consiste en tomar la idea de CdI desarrollada por Hewings et al. 1989, la que posteriormente es ampliada por Aroche, 1996, 2002 y en 2005, a lo que se agrega el enfoque de la sensibilidad planteado por Schintke \& Stäglin, 1988.

Para obtener los CdI, se toma como limite tolerable un error del $1 \%$ ( $p=1 \%$ ) y unos valores para los $r_{i j}$ menores e igual a un 15\% (los $r_{i j}$ deben ser entendidos como elasticidades, así; por ejemplo, un $r_{i j}=15$, indica que para que aumente la producción de la actividad j-ésima en más de un 1\%, la etapa productiva i-ésima debe modificarse en un $15 \%$; esto es, el coeficiente técnico $\mathrm{a}_{\mathrm{ij}}$, debe modificarse en un $15 \%$ para que la producción sectorial se incremente en un 1\%), seleccionada la información más sensible, se construye a partir de la misma las respectivas matrices Booleanas, las que servirán a su vez de insumo para confeccionar los distintos CdI.

\section{RESULTADOS Y DISCUSIÓN}

Para evaluar en forma más precisa la magnitud del impacto de cada sector sobre la producción de la economía ${ }^{8}$, utilizaremos los multiplicadores de producción ponderados (MPM). Un multiplicador de producción ponderado por la intensidad en términos

8 Obtenidos de la matriz MPM (ver anexo, para la identificación de la actividad y la magnitud de su multiplicador). 
Tabla 1. Los 10 mayores MPM por actividades según cada economía

\begin{tabular}{|c|c|c|c|}
\hline $\begin{array}{l}\text { SECTOR/ } \\
\text { ECONOMİA }\end{array}$ & EXTRACTIVO [TOTAL] & MANUFACTURERO [TOTAL] & $\begin{array}{l}\text { SERVICIOS } \\
\text { [TOTAL] }\end{array}$ \\
\hline Chile & $\begin{array}{l}\text { Ganado, prod. pecuarios y } \\
\text { carne (3) y; pescados, mariscos y } \\
\text { productos del mar (5); [2]. }\end{array}$ & $\begin{array}{l}\text { Conservas (9); prod. lácteos (11); alimentos } \\
\text { animales (14); vidrio y minerales no metálicos } \\
\text { (20); muebles (23) y; otros productos (24); [6]. }\end{array}$ & $\begin{array}{l}\text { Electricidad (25) } \\
\text { y; comunicaciones } \\
\text { (33); [2]. }\end{array}$ \\
\hline Arica & $\begin{array}{l}\text { Productos agrícolas (1); ganado, } \\
\text { prod. pecuarios y carne (3) y; } \\
\text { Productos silvícolas; Maderas y } \\
\text { Papel (4); [3]. }\end{array}$ & $\begin{array}{l}\text { Conservas (9); molinería, pan, pastas y fideos } \\
\text { (12); licores, cervezas, analcohólicas y vinos (15); } \\
\text { vidrio y minerales no metálicos (20); maquinaria } \\
\text { y equipo eléctrico y no eléctrico (22); muebles } \\
\text { (23) y; otros productos (24); [7]. }\end{array}$ & $--:[0]$. \\
\hline Punta Arenas & $\begin{array}{l}\text { Productos agrícolas (1); frutas } \\
(2) ; \text { ganado, productos pecuarios } \\
\text { y carne (3) y; petróleo y } \\
\text { combustibles y lubricantes (6); [4]. }\end{array}$ & $\begin{array}{l}\text { Molinería, pan, fideos y pastas (12); licores, y } \\
\text { bebidas analcohólicas (15); textiles, prendas } \\
\text { de vestir, cueros y calzados (17); productos } \\
\text { químicos, caucho y de plástico (19) y; productos } \\
\text { del hierro, acero y metálicos (21); [5]. }\end{array}$ & $\begin{array}{l}\text { Servicios de } \\
\text { transporte } \\
\text { marítimo y aéreo } \\
\text { (31); [1]. }\end{array}$ \\
\hline
\end{tabular}

Tabla 2. Actividades "claves" según cada economía y tipo de sector.

\begin{tabular}{|c|l|l|l|}
\hline $\begin{array}{c}\text { SECTOR/ } \\
\text { ECONOMIIA }\end{array}$ & \multicolumn{1}{|c|}{ EXTRACTIVO [TOTAL] } & \multicolumn{1}{|c|}{ MANUFACTURERO [TOTAL] } & SERVICIOS [TOTAL] \\
\hline Chile [7] & $\begin{array}{l}\text { Ganado, productos pecuarios y carne } \\
\text { (3) y; silvicultura, maderas y papel (4); } \\
\text { [2]. }\end{array}$ & $\begin{array}{l}\text { Alimentos para animales (14) e; } \\
\text { impresos-grabaciones (18); [2]. }\end{array}$ & $\begin{array}{l}\text { Electricidad (25); comercio (28) } \\
\text { y comunicaciones (33); [3]. }\end{array}$ \\
\hline Arica [2] & $\begin{array}{l}\text { Productos agrícolas (1) y; ganado, } \\
\text { prod. pecuarios y carne (3); [2]. }\end{array}$ & $--;[0]$. & $--;[0]$. \\
\hline $\begin{array}{c}\text { Punta Arenas } \\
{[4]}\end{array}$ & $\begin{array}{l}\text { Petróleo crudo, combustibles y y } \\
\text { lubricantes (6); [1]. }\end{array}$ & $\begin{array}{l}\text { Productos químicos, caucho y de } \\
\text { plástico (19); [1]. }\end{array}$ & $\begin{array}{l}\text { Comercio (28) y transporte } \\
\text { terrestre (30); [2]. }\end{array}$ \\
\hline
\end{tabular}

Tabla 3. Actividades "claves" según cada economía, tipo de sector y los tres tipos de encadenamientos.

\begin{tabular}{|c|l|l|l|}
\hline $\begin{array}{c}\text { SECTOR/ } \\
\text { ECONOMİ }\end{array}$ & \multicolumn{1}{|c|}{ EXTRACTIVO [TOTAL] } & \multicolumn{1}{|c|}{ MANUFACTURERO [TOTAL] } & \multicolumn{1}{c|}{ SERVICIOS [TOTAL] } \\
\hline Chile [4] & $\begin{array}{l}\text { Ganado, productos pecuarios y de } \\
\text { la carne (3); [1]. }\end{array}$ & $\begin{array}{l}\text { Alimentos para animales (14) e; } \\
\text { impresos y grabaciones (18); [2] }\end{array}$ & Servicios comerciales (28); [1]. \\
\hline Arica [1] & Productos agrícolas (1); [1]. & $--;[0]$. & $--;[0]$. \\
\hline $\begin{array}{c}\text { Punta Arenas } \\
{[4]}\end{array}$ & $\begin{array}{l}\text { Petróleo, combustibles y } \\
\text { lubricantes (6); [1]. }\end{array}$ & $\begin{array}{l}\text { Productos químicos, de caucho y } \\
\text { plástico (19); [1]. }\end{array}$ & $\begin{array}{l}\text { Comercio (28) y transporte } \\
\text { terrestre (30); [2]. }\end{array}$ \\
\hline
\end{tabular}

de volumen de la matriz inversa de Leontief, mide el incremento en la producción total de la economía, consecuencia de un incremento de una unidad en la demanda final del sector.

La Tabla 1, muestra cuales son los 10 mayores multiplicadores de las 40 actividades analizadas por cada economía. Tal cuadro, devela que en el año 2008, Chile presentaba una estructura relativamente diversificada, concentrando el $60 \%$ de los mayores multiplicadores en la industria manufacturera (2 en sector extractivo; 6 en el manufacturero y 2 en servicios). En Arica, llama la atención que sólo se encuentren actividades con altos MPM en los sectores extractivo y manufacturero. Lo interesante de ello está en sus magnitudes pues, los mayores están en el sector primario. El resto de las actividades, se encontrarían en el sector industrial con un patrón similar al de la economía chilena. Para el caso de Punta Arenas, 4 de sus mayores multiplicadores se encontraban en el sector primario, 5 en el industrial y finalmente, sólo una actividad en el sector servicio con un multiplicador de producción igual a 2, 56.

En comparación con Chile, sólo el sector ganado, productos pecuarios y carne (3) en la comuna de Arica presenta un MPM por sobre el promedio nacional $(1,78)$. Arica tiene por ventaja, una mayor 
diversificación y homogeneidad industrial en términos de multiplicadores, los cuales son inferiores en su totalidad a los de Chile, pero más diversificados que los de Punta Arenas. En el caso de Arica, de las 12 actividades manufactureras que se realizaban, 7 corresponden a los mayores multiplicadores y de los 5 restantes, dos están por sobre el promedio, lo que indica lo encadenado de sus actividades, aspecto que no se observa en Chile o en Punta Arenas.

Basados en éstos resultados, se plantea el posible siguiente escenario; si a la economía chilena se le incentiva, tales políticas seguramente tendrán en consideración los efectos que éstas tangan sobre la industria manufacturera y el sector servicios, quedando fuera por tanto, las regiones extremas, en especial Punta Arenas que se caracteriza por una alta y concentrada especialización en la industria del metanol, careciendo de una importante industria manufacturera encadenada entre si; por su parte, en Arica, que si bien muestra una alta e interconectada actividad industrial se habría visto favorecida, dado que no obedece a una alta ni concentrada especialización, pero hoy en día tal actividad ésta muy deprimida (ya que actualmente no están presente la industria textil, ni automotriz, ni en parte la de alimentos); por tanto, ambas regiones pierden oportunidades de crecimiento.

La Tabla 2 muestra las actividades "claves". Las actividades "claves" son aquellas que dan mayor dinamismo al sistema económico, dado que para su desarrollo se demanda y ofertan insumos al sistema económico por sobre el promedio ${ }^{9}$. En Chile existían 7 para el año 2008, 2 en la industria primaria; 2 en la industria manufacturera y, 3 en el sector servicios $^{10}$. En Punta Arenas sólo 4; una tanto en el sector extractivo como en el manufacturero y, dos en servicios. En Arica, se detectaron solamente dos, encontrándose en el sector extractivo. Respecto a Chile, tanto Arica como Punta Arenas presentan una similitud, ganado, productos pecuarios y carne (3) y, comercio (28), respectivamente. Entre Arica y Punta Arenas, no se observan coincidencias.

De acuerdo a la definición de Hirschman (1958), una economía se desarrolla más, cuando tiene

9 En anexo, se da un detalle del tipo de actividad, en función de lo que demande u ofrezca de insumo al resto del sistema económico.

10 Para un mayor detalle de las tipologías y valores de las 40 actividades, véase el anexo. más actividades claves en sectores que promueven el crecimiento de otras actividades vía encadenamientos productivos. Por lo que una aproximación para medir el nivel de desarrollo de las economías, estará dado por el número de sectores claves existentes.

Los resultados muestran que en Arica sólo se encuentran dos sectores claves, mientras que en Punta Arenas aparecen 4 de las 40 actividades analizadas en cada caso (ver Tabla 2). Este número de actividades claves también reflejan el bajo desarrollo de las economías extremas del país. Por otra parte, la economía nacional muestra 7 actividades claves, reflejando un nivel de desarrollo mayor pero aún bajo comparado con una economía desarrollada, la que normalmente muestra un número de sectores claves superior al $25 \%$ de los sectores analizados. Como se puede observar, las regiones extremas, nuevamente quedan fuera de posibles políticas nacionales, en el entendido de que, la aplicación de políticas macroeconómicas nacionales, irían en la lógica de potenciar sectores tales como; por ejemplo, ganado, productos pecuarios y carne (3) y; silvicultura, maderas y papel (4).

Desde el punto de vista de los encadenamientos indirectos totales ( $\mathrm{BLi}$ y $\mathrm{FLi}$, respectivamente) e indirectos sobre otras actividades (BLz y FLz; ver anexo), no se observan coincidencias. Arica, no presenta ninguna similitud con Chile ni con Punta Arenas. Punta Arenas, coincide con Chile sólo en el sector comercio (28).

Considerando los tres tipos de encadenamientos (totales, indirectos e indirectos con otras industrias; Tabla 3). Tanto en el caso de Chile como de Punta Arenas, se observan cuatro actividades claves bajo los tres escenarios. Arica, presenta sólo una actividad clave (sector primario) que no coincide con las otras economías.

Un aspecto interesante de revisar es la persistencia de la importancia de los impactos que genera una actividad cuando se aíslan determinados efectos; por un lado, con el objeto de corregir la influencia de los altos niveles de autoconsumo e impactos indirectos que se auto genera y; por otro, como una forma de evaluar los impactos indirectos que induce hacia el resto del sistema económico. En tal sentido, se parte de la premisa que existe un "efecto total" que esta formado por los impactos directos, indirectos incluyendo los propios e, indirectos hacia el resto del sistema económico (se excluyen 
los directos e indirectos propios); en éste contexto, una actividad será verdaderamente "articuladora de desarrollo", en la medida que dichos efectos sean altamente dispersos y además, se afecte más al sistema en un sentido de demanda y oferta de insumos independientemente de las condiciones en que ello se analice. En el caso de Chile, se detecto que inicialmente, productos silvícolas, de madera y papel (4); electricidad (25) y comunicaciones (33), eran "claves", e incluso mantenían esa "clasificación cuando se consideraban sus efectos indirectos totales, sin embargo, cuando se limita el estudio a los efectos sobre otras industrias solamente, se observa que ellas no ejercen mayor influencia sobre el resto del sistema, siendo estas o "base" o del tipo "independiente", por tanto, sus efectos son más bien acotados y referidos a su propio entorno, no impactando al desarrollo de otras actividades. En Punta Arenas, el cambio sólo se observa con los productos químicos (19) y, en Arica con ganado, productos pecuarios y de la carne (3).

Actividades que inicialmente no eran "claves" pero que al aislar sus efectos resultaron serlo. En Chile no se observan. En Punta Arenas, habrían cambiado dos de ellas (construcción (27) y comunicaciones (33), las que originalmente eran "impulsora de la economía" e "independiente", respectivamente. En Arica, la industria química (19),originalmente era "impulsora" y luego resulto ser "clave". Este último aspecto es interesante, dado que actividades que inicialmente se mostraban como ajenas a la generación de desarrollo ahora se manifiestan como motivadoras del mismo.

De ésta forma, quedan en evidencia dos aspectos; primero, que no todas las actividades que inicialmente son "claves" o preponderantes para el desarrollo mantiene su importancia cuando se aíslan determinados impactos y; segundo, la discrepancia observada entre lo que ocurre a nivel nacional y las regiones, en tal sentido, las regiones extremas quedan fuera casi de la totalidad de las posibles políticas macroeconómicas, ya que las mismas no estarían focalizadas en sus respectivas realidades.

Resumiendo, desde el punto de vista de los multiplicadores de producción y encadenamientos. La economía menor que presenta mejores condiciones en pro del desarrollo local, es Punta Arenas. De igual forma llama la atención, como en ésta localidad una misma actividad que se desarrolla en las tres economías tiene menos repercusiones positivas; en concreto, nos referimos a los productos químicos (19). En el caso de Arica, tal actividad basada principalmente en la producción de Borax, tiene importantes implicancias a nivel local (obsérvese que son "claves" su BL y FL indirectos), sin embargo, la misma en Punta Arenas, basada en el Metanol, la cual en términos de PIB aportó más, afectó a su entorno en forma bastante más acotada al no presentar importantes repercusiones indirectas.

Las economías menores, no estarían en sintonía con la estructura que se toma como patrón de comparación. No existen coincidencias en actividades "claves"-sólo se observa una y es en comercio (28)-, éste aspecto puede jugar en contra para estas economías menores, al no estar conectados a estructuras de desarrollo globales (ie: políticas de cooperación, tributarias, spillovers, economías marshalianas, etc).

Basados en la técnica de las MPM, la Fig. 2 muestra cuáles fueron las 10 actividades más importantes para Chile durante el año 2008. Como se puede apreciar, la gráfica señala una distribución uniforme y proporcional en términos de los impactos que las actividades manifiestan, siendo ligeramente mayores sus respectivos $\mathrm{BL}$ frente a sus FL. Adicionalmente, su estructura da cuenta de una economía que vincula las actividades propias de los servicios (actividades de la 25 a 40) con las de las actividades primarias (de 1 a 8), observándose poca interrelación entre los servicios con la industria manufacturera (productos 9 a 24).

Desde el punto de vista de los impactos de las etapas productivas (Fig. 2, 3, 4 y 5), se observa que de las 10 funciones más importantes para cada economía, 4 serían coincidentes entre ellas, siendo éstas ordenadas jerárquicamente en base a su importancia en Chile, servicios empresariales (35); comercio (28); productos químicos de caucho y plásticos (19) y; transporte terrestre (30).

Si se observan las MPM de las tres economías (en concreto; Figs. 2, 3 y 4), se aprecia la similitud gráfica que existe entre ellas (los tres gráficos muestran una caída homogénea desde el vértice superior del fondo, hasta en vértice inferior del frente), la diferencia es justificada por los impactos que tienen los multiplicadores de las actividades 28 (comercio) en Arica y 19 (industria química) en Punta Arenas. Del ejercicio realizado, se concluye, que los multiplicadores de la economía nacional son homogéneos, bajos y 
disminuyen en forma relativamente proporcional con la excepción del sector servicios empresariales (35), aspecto que se repite en Arica y Punta Arenas, con las particularidades del sector comercio e industria química respectivamente, situación que cambia cuando a la economía austral se le eliminan del gráfico los productos químicos (Fig. 5), obteniéndose una gráfica más acorde a la nacional, y similar a la de Arica.

En las regiones extremas es importante la presencia de la Administración Pública (37), en especial en la zona austral. De igual forma, también se constata que éstas economías, basan su desarrollo en el sector manufacturero y de servicios, en especial Arica, en donde se concentran 6 de las 10 actividades más importantes en éste último sector, dejando 2 en el sector primario e igual número en el industrial. En Punta Arenas, la distribución seria; 5 (primario); 4 (manufacturero) y 1 (servicios).

Desde una perspectiva más estructural, la Fig. 6, manifiesta las diferencia en términos de impacto que tienen en Arica las 10 etapas productivas más importantes de tal economía respecto a la estructura de Chile. Si las economías son similares, debiera observarse una distribución espacial similar a la obtenida para Chile (Fig. 2), semejanza que en el caso de Arica no ocurre.

La estructura económica que manifiesta Arica, se observa diferente respecto a su patrón de comparación en dos sentidos; por un lado, los impactos no presentan la misma distribución proporcional que la economía nacional y; por otra parte, la valoración de los mismos es menor. En Arica el comercio juega en un rol más preponderante que la misma a nivel nacional, sus efectos a nivel local son mayores que los observados bajo un contexto nacional.

Similar al caso anterior, el gráfico de la Fig. 7, confirma las diferencias entre la economía de Punta Arenas y la chilena, en términos del impacto que tienen en la economía de Punta Arenas las 10 funciones de producción más importantes de Chile en ella. Un caso particular, es la industria química en la economía austral, la que presenta impactos superiores a la nacional dada su especialización, pero en términos de relación interindustrial sus efectos son muchos más acotados al contrario de lo que ocurre a nivel nacional.

Con el fin de detectar las diferencias entre Punta Arenas y Arica respecto a la estructura nacional, se retira de la primera la industria química
(19; Fig. 5). En tal situación, la estructura de Punta Arenas se presenta similar a la de Arica, al menos en términos gráficos, no así con sus multiplicadores que, en general, se muestran mayores que los de Arica.

En lo referido a los impactos, se observa que las diferencias son bajas y a favor de Punta Arenas, lo que permite concluir dos cosas; por un lado, el poco impacto que tienen las actividades del norte frente a lo que ocurre en el sur-austral y; por otra parte, que la economía de Punta Arenas, aunque presente una estructura diferente a la de Chile, transmite un mayor efecto dada la magnitud de los impactos obtenidos de su MPM y por la articulación de sus actividades (encadenamientos), aspecto que no se observa en Arica.

Para responder a ¿qué economía de las menores se encuentra con más ventajas frente a la estructura de Chile?, se realiza el ejercicio de traspasar la estructura de las etapas productivas de la matriz MPM de Chile, a las economías menores para posteriormente realizar una resta entre ellas ${ }^{11}$ (Fig. 8). De tal ejercicio se concluye que la economía de Punta Arenas presentó más ventajas estructurales, pues de las 10 actividades más importantes en Chile, no se detectaron diferencias importantes a favor de Arica.

Los CdI, permiten apreciar cuáles son las actividades que desde el enfoque de la sensibilidad de sus respectivas etapas productivas afectan más al resto del sistema económico. La idea intuitiva que rige ésta metodología es aglutinar etapas productivas sensibles que frente a pequeños cambios en ellas generan cambios del $1 \%$ en la producción (en éste caso, cambios menores o igual a un $15 \%$ en alguna de las etapas productivas de sus respectivas funciones de producción); de esta forma, a mayor número de etapas sensibles, mayores serán los CdI que se formen y, mientras más de estos existan, más desarrollada será la economía.

Para comprender lo que continua, puede observarse el grafo dirigido Fig. 9, en concreto analizar la actividad número 14 (alimentos para animales), a tal nodo llega una fecha proveniente de la actividad 1 (productos agrícolas) y salen de ella dos, una en dirección a la actividad número 3 (ganado; productos

11 Esto es, se mantiene el etiquetado que impuso la estructura de la economía nacional, y luego se realiza una resta entre las MPM de Punta Arenas y Arica. 


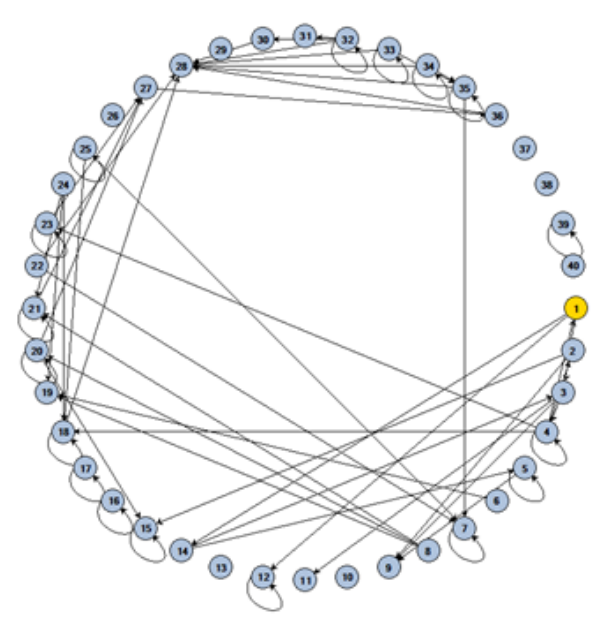

Fig. 9 CdI para la economía chilena en 2008.

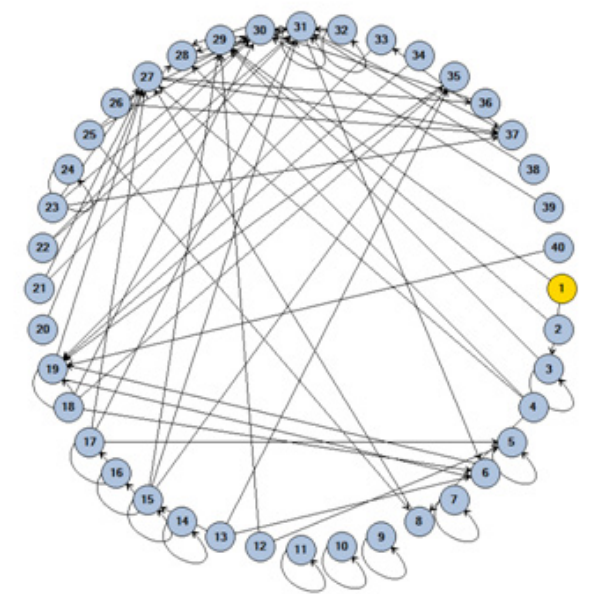

Fig. 11 CdI para la economía de Punta Arenas en 2007.

pecuarios y carne) y la otra a la número 5 (pescados, mariscos y productos del mar industrializados (la que incluye la industria acuícola). Entonces, la actividad 14, presenta unos CdI, formados por las actividades 1, 3 y 5 (grupo de actividades que por lo demás se pueden considerar como un clúster). Por otra parte, tal grafo indica que, para incrementar la producción de la actividad 1 en un $1 \%$, requiere que el coeficiente técnico $\mathrm{a}_{1 ; 14}$, se modifiquen como máximo en un $15 \%$ (en estricto rigor en un $8,00 \%$ ); es decir, si se incrementa la producción de alimentos para animales, aumenta la producción de los productos agrícolas. Por su parte, si las etapas de la actividad 14 vinculadas con el ganado y los pescados $\left(\mathrm{a}_{14 ; 3}\right.$ y $\left.\mathrm{a}_{14: 5}\right)$, se incrementan en menos de un $15 \%$ cada una (en concreto 2,48 y $3,67 \%$ respectivamente),

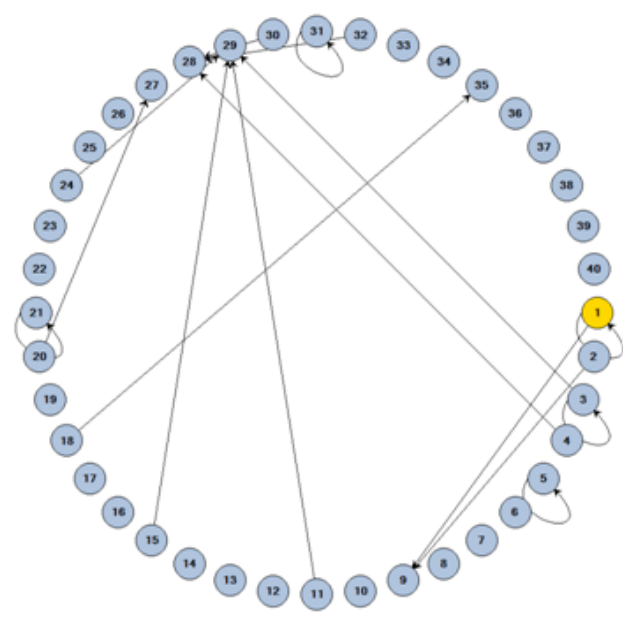

Fig. 10 CdI para la economía de Arica en 2007.

se incrementará en un $1 \%$ las producciones de las actividades 3 y 5 simultáneamente. En tal sentido, si los requerimientos de alimentos por parte de ganados o pescados aumentan, se favorece indirectamente a la agricultura.

Basados en la Fig. 9, se observa que para el caso de Chile, existen 10 actividades que ayudan a formar un entramado difuso (Fig. 9, Tabla 4), siendo las actividades, que más contribuyen a dar profusión al entramado; cobre (7); construcción (27); comercio (28) y servicios empresariales (35), partir de los cuales por tanto, se puede ver la generación de variados clúster.

Lo anterior, manifiesta un retroceso, dado que cuando se considera la estructura que presentaba Chile en; por ejemplo, el año 2003 (Fig. 12), ésta economía se presentaba más entrelazada o profusa que la del año 2008, lo que indica que se estaba en presencia de una economía más desarrollada en términos de profusión de actividades y división de las mismas (Soza-Amigo, 2012). La razón del cambio se puede deber a dos aspectos, por un lado, a la alta influencia del precio del cobre en la Cuentas Nacionales; o bien, a que la economía ha ido en retroceso en términos de desarrollo.

Los CdI que se forman en Arica (Fig. 10 y Tabla 4), muestran el contraste que existe entre ésta economía frente a la economía nacional y la del sur-austral, su escasa profusión, hace alusión a una economía que se comienza a desarrollar en forma muy incipiente, haciendo difícil intervenir el desarrollo local. La poca presencia de actividades 
Tabla 4. CdI, según cada economía y tipo de sector.

\begin{tabular}{|c|c|c|c|}
\hline $\begin{array}{l}\text { Sector/ } \\
\text { Economia }\end{array}$ & Extractivo [total] & Manufacturero [total] & Servicios [total] \\
\hline Chile [10] & $\begin{array}{l}\text { productos silvícolas de } \\
\text { maderas y papel (4); cobre } \\
\text { (7) y otros minerales (8); [3]. }\end{array}$ & $\begin{array}{l}\text { conservas (9); alimentos para } \\
\text { animales (14); impresos y } \\
\text { grabaciones (18) y otros productos } \\
(24) ;[4] .\end{array}$ & $\begin{array}{l}\text { productos de la construcción } \\
\text { (27); comercio (28) y servicios } \\
\text { empresariales (35); [3]. }\end{array}$ \\
\hline Arica [5] & $--;[0]$. & conservas (9); [1]. & $\begin{array}{l}\text { construcción (27); comercio (28); } \\
\text { hostelería y restaurantes (29); s. } \\
\text { empresariales (35); [4]. }\end{array}$ \\
\hline $\begin{array}{l}\text { Punta } \\
\text { Arenas [18] }\end{array}$ & $\begin{array}{l}\text { productos silvícolas, de } \\
\text { maderas y papel (4); } \\
\text { pescados, mariscos y } \\
\text { productos del mar (5); } \\
\text { petróleo crudo, combustible } \\
\text { y lubricantes (6) y; otros } \\
\text { minerales (8); [4]. }\end{array}$ & $\begin{array}{l}\text { licores, bebidas (15); textiles, cuero y } \\
\text { calzado (17); impresos y grabaciones } \\
\text { (18); prod. químicos, de caucho } \\
\text { y plásticos (19); prod. básicos del } \\
\text { hierro, acero y metálicos (21); maq. } \\
\text { y equipo eléctrico y no eléctrico (22) } \\
\text { y muebles (23); [7]. }\end{array}$ & $\begin{array}{l}\text { electricidad (25); construcción } \\
\text { (27); comercio (28); hotelería } \\
\text { y restaurantes (29); transporte } \\
\text { marítimo y aéreo (31); servicios } \\
\text { empresariales (35) y admi. pública } \\
\text { (37); [7]. }\end{array}$ \\
\hline
\end{tabular}

sensibles más las bajas repercusiones de las actividades encadenadas, indicarían que es necesario disponer de pocos pero focalizados recursos para generar cambios en la producción.

Al disponer de los CdI de Punta Arenas de los años 2003 y 2007, se puede apreciar la evaluación de los mismos (Fig. 10 y 12, Tabla 4). En el período de 5 años se observa, el aumento de los CdI, los que son más interrelacionados que los de la economía chilena en 2008 y; como la economía deja de basarse en la producción de un commodities (metanol) y pasa a transformarse en otra más diversificada y orientada a los servicios.

Al revisar en conjunto los $\mathrm{CdI}$ de Arica y Punta Arenas, se observa como estas dependen de actividades vinculadas a la construcción y el turismo, aunque el desarrollo éste último al menos para el caso de Magallanes según otros estudios, es incipiente pero con altas posibilidades de impacto (Soza-Amigo \& Aroca, 2012 y Soza-Amigo \& Maripani, 2012).

En resumen, los $\mathrm{CdI}$ entregan antecedentes adicionales que permiten confirmar la necesidad de aplicar políticas particulares a las regiones; en especial, a las extremas. Nótese que una de las actividades que ayudan a formar "clúster" en Chile, es la minería; $y$ en concreto, la producción del cobre, mineral que afecta sustancialmente en el valor del dólar y, a los ingresos que recibe el país para financiar sus respectivas políticas públicas; es decir, se observa que la autoridad frente a los distintos vaivenes de la economía, debiera tomar medidas considerando las repercusiones que ellas tendrán sobre tal actividad, afectando por tanto a las regiones que no basan su desarrollo en ésta minería.

Frente a la pregunta ¿en cuántas y en cuáles actividades y productos sería más adecuado aplicar Políticas Públicas en pro de inducir un desarrollo en las regiones extremas?, se contabilizan aproximadamente 9 (4 (productos silvícolas de madera y papel); 12 (molinería, pan, fideos y pastas); 18 (impresos y grabaciones); 27 (construcción); 28 (comercio); 29 (hostelería y restaurantes); transportes en general (30 y 31) y; 35 (servicios empresariales)). Tener en consideración esto es importante entre otras causas por las siguientes; primero, es relativamente fácil impulsar la construcción desde el sistema público; segundo, ambas regiones cuentan con condiciones naturales para explotar el turismo, presentando además actividades "sensibles" que se vinculan al mismo (comercio, restaurantes y hoteles y, transporte y comunicaciones) y; tercero, dado que políticas nacionales tendría repercusión colectivas y se harían más efectivas dada la sensibilidad de las distintas actividades en los extremos.

\section{CONCLUSIONES}

El trabajo deja de manifiesto que existen notorias diferencias entre las economías extremas y el patrón de comparación. Oportunidades para desarrollar los extremos existen, tales economías frente a pequeños estímulos debieran reportar consecuencias en función del impacto que generan sus multiplicadores, los tipos de encadenamientos y CdI que presenten, el cómo ocurra y la velocidad en que ello se dé, es algo que depende de las políticas globalizadas o focalizadas que se empleen.

Punta Arenas, que se toma como referente de la región de Magallanes y Antártica Chilena, se manifiesta como una economía con claras ventajas 
respecto a la comuna de Arica, su estructura más encadenada con CdI más entrelazados y la dinámica que arrastra, con variadas actividades de posible intervención, a lo que se suma un creciente sector servicio, proceso común en las economías más evolucionadas, permiten concluir que se ésta en presencia de una estructura más desarrollada y en mejores condiciones para consolidar el mismo.

Respecto a las actividades que dinamizan la economía en Punta Arenas, ellas estarían vinculadas a la industria manufacturera y el sector servicio, destacando de éste último, construcción, comercio, transporte y restaurantes y hoteles. Además la estructura de ésta economía bajo el esquema MPM, si bien se presenta con bajos impactos y disímil gráfica respecto a la economía nacional, siendo la excepción la industria química, dada la especialización en la producción de metanol, su estructura se acerca a la que presenta Chile, siendo a la vez más encadenada y entrelaza que la de Arica.

La situación en Arica, es distinta y se presenta como la menos favorecida de las tres economías estudiadas, si en Punta Arenas se observa una serie de actividades inductoras de desarrollo, en Arica, no sólo son escasas, sino que además la estructura se presenta pobre, con escasos y débiles encadenamientos, a lo que se suma una ausencia casi total de actividades entrelazadas, las que evitan incrementar sus posibles CdI, al menos en el corto plazo.

Finalmente, se desprende que las regiones extremas requieren de políticas públicas distintas del contexto nacional e incluso entre sí, estas regiones no sólo son disímiles de la estructura nacional, sino que se observa que la actividad chilena y su estructura económica, está fuertemente vinculada a lo que ocurra con la producción y precio del cobre, el cual a su vez afecta al gasto público y al precio del dólar; por tanto, las políticas nacionales al estar pensadas en resultados macroeconómicos y seguramente considerando el cómo ellas afecten la producción del cobre, difícilmente impactaran positivamente a éstas regiones, de allí que se requiere políticas focalizadas en ellas y no pensadas en un contexto macroeconómico que les quita espacio para seguir creciendo. La mejor prueba de ello es el caso de Arica que al mostrar un desarrollo incipiente, depende fuertemente de la actividad agrícola, la que debiera verse afectada cuando baja el precio del dólar. El caso de Punta
Arenas es distinto, dado que presenta, por un lado, altos salarios pero bajos bienes públicos de calidad $y$, por otra parte, tal economía hoy en día dispone de menos cantidad de recursos naturales, los que en antaño le dieron distinción económica por sus aportes al PIB pero bajo desarrollo. Otra alternativa, es focalizar los recursos en lo que hemos llamado identidad productiva, así en el caso de Arica, sus potencialidades se vinculan al turismo y agricultura, mientras que en Punta Arenas, tales actividades parecieran ser rezagadas respecto a la influencia que se observa en el sector servicios.

\section{BIBLIOGRAFÍA}

Aroca, P. \& Atienza, M. (2011). Economic implications of long distance commuting in the Chilean mining industry. Resources Policy, 36(3), 196-203.

Aroca, P. \& Atienza, M. (2008). Conmutación Regional en Chile y su Impacto en la Región de Antofagasta. EURE, XXXIV(102),97-120.

Aroche, F. (2005). Desintegración en la estructura productiva mexicana y el empleo. Los coeficientes importantes y su importancia en la integración. Revista Asturiana de Economía, 32, 31-62.

Aroche, F. (2002). Structural transformations and important coefficients in the North American economies. Economic Systems Research, 14(3), 257-273.

Aroche, F. (1996). Important coefficients and structural change: A multi-layer approach. Economic Systems Research, 8(3), 235-246.

Atienza, M. \& Aroca, P. (2012). Concentración y Crecimiento en Chile: Una relación negativa ignorada. EURE, 38(114), 257-277.

Brandao, J. (1973). Migración y Desarrollo. EURE, 9(3),117-125.

Imbs, J. \& Wacziarg, R. (2003).Stages of Diversification. The American Economic Journal, 93(1),63- 86.

Hewings, G., Sonis, M., Guo, P, Israilevich, P. \& Schindler, G. (1998). The Hollowing out Process in the Chicago Economy: 1975- 2011. Geographical Analysis, 30(3), 217-233.

Hewings, G., Fonseca, M., Guilhoto, G., \&Sonis, M. (1989). Key sectors and structural change in the Brazilian economy: A comparison of alternative approaches and their policy implications. Journal of Policy Modeling, 11(1),67-90.

Hewings, G., Jensen, R.C. \& West, G.R. (1988).Fields of Influence of Technological Change in Input- Output Models. Papers of Regional Science Association, 64, 25-36.

Hidalgo, C. \&Hausmann, R. (2009).The building blocks of eco- 
nomic complexity. Proceedings of the National Academy of Sciences USA (PNAS), 106(26), 10570- 10575.

Hidalgo, C. \& Hausmann, R. (2008). A Network View of Economic Development. Developing Alternatives, 12(1), 5-10.

Hidalgo, C., Klinger, B., Barabási, A.L. \& Hausmann, R. (2007). The Product Space Conditions the Development of Nations. Science, 317, 482-487.

Hirschman, A. (1958). The strategy of economic development. New Haven, Connecticut, USA, Yale University Press.

Holub, H. \&Schnabl, H. (1994). Input-output-rechnung: Input-output-analyse. Munchen, Wien: Oldenbourg.

Leontief, W. (1963). The Structure of Development. Scientific American, 209,148-166.

Rasmussen, P. (1956). Studies in inter-sectoral relations. Amsterdam, North- Holland P. C.

Sarrias, M. \& Aroca, P. (2012). Regional Business Cycle Synchronization in Chile. En: Serie de Documentos de Trabajo en Economía- UCN (IDEAR). Antofagasta: Universidad Católica del Norte, Facultad de Economía y Administración.

Schintke, J. \& Stäglin, R. (1988). Important input coefficients in market transaction tables and production flow tables. In: M. Ciaschini(Ed.), Input-Output Analysis, Current Developments. New York: Chapman and Hall.

Schnabl, H. (1994). The evolution of production structures, analyzed by a multi-layer procedure. Economic Systems Research, 6(19),51-69.

Sebald, A. (1974). An analysis of the sensitivity of large scale input-output models to parametric uncertainties. Urbana: Center for Advanced Computation, document $\mathrm{N}^{\circ} 122$, University of Illinois.

Sonis, M \&Hewings, G. (2009). New Developments in Input-Output Analysis: Fields of Influence of Changes, the Temporal Leontief Inverse and the Recosinderation of Classical Key Sector Analysis. In:M. Sonis \& G. Hewings (Eds.), Tool Kits in Regional Science: Theory, Models, and Estimation. Ney York: Springer.

Soza-Amigo, S. \& Aroca, P. (2012). Simulation and Analysis of Punta Arenas Economy Based on Input-Output Tables 2003 and 2007. Magallania, 40(2), 113-127.
Soza-Amigo, S. \& Aroca, P. (2011). Small, Isolated and Commodities Dependent Economies: The case of the Oil and Methanol in the County of Punta Arenas, Chile. Magallania, 39(2),113-135.

Soza-Amigo, S. \& Aroca, P. (2010). Lost Opportunities in Magallanes. Magallania, 38(2), 89-101.

Soza-Amigo, S. \& Maripani, J. (2012). Cambios Estructurales y Efecto del Turismo en Punta Arenas: Análisis de las matrices input- output 2007 y 2003. Punta Arenas: Ediciones Universidad de Magallanes.

Soza-Amigo, S. (2012). Semejanzas Estructurales Entre Economías con Distinto Nivel de Desarrollo: Comparativa input-output para Argentina y Chile versus otras economías. En: XIV Reunión de Economía Mundial, Universidad de Jaén, 30-31 de Mayo y 1 de Junio, Jaén, España.

Soza-Amigo, S. (2011). Linkages and Structural Similarities for the Regions of Chile. Economic Analysis Review, 26(2), 81-110.

Soza-Amigo, S. (2008). Análisis comparativo para la economía magallánica desde la perspectiva del enfoque input-output. Economic Analysis Review, 23 (2), 95-120.

Thakur, S. (2011). Fundamental Economic Structure and Structural Change in Regional Economies: A methodological approach. Régionet Développement, 33, 9- 38.

Thakur, S. (2010). Identification of Regional Fundamental Economic Structure (FES): An Input-Output and Field of Influence Approach. In: Amelia U. Santos-Paulino \& Guanghua Wan (Eds.), The Rise of China and India: Impacts, prospects and implications. Palgrave-Macmillan.

Thakur, S. (2008). Identification of Temporal Fundamental Economic Structure (FES) of India: An Input- Output and Cross-Entropy Analysis. Structural Change and Economic Dynamics, 19(2), 132- 151.

West, G. \& Brown, R. (2003).Structural Change, Inter Sectoral Linkages and Hollowing Out in the Taiwanese Economy, 1976-1994, Unpublished Paper, School of Economies, The University of Queensland. 


\section{ANEXOS}

Formulaciones que determinan el tipo de igualdades para una MIP y encadenamiento según las distintas técnicas empleadas (hacia atrás (BL) y delante (FL)).

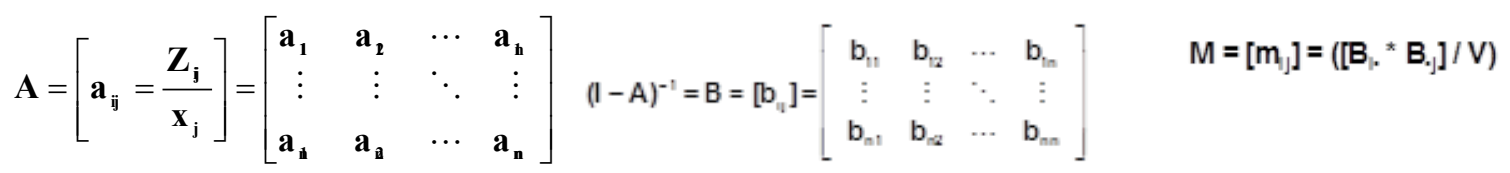
Donde: Intensidad de la Matriz Inversa de Leontief $\mathbf{x}_{\mathbf{j}}=$ producción del sector j-ésimo.

$$
V=\sum_{i=j} b_{I}
$$

Multiplicador de Producción Ponderado

$$
\mathrm{O}_{\mathrm{J}}=\sum_{1=1}^{\mathrm{n}} \mathrm{m}_{\mathrm{J}}
$$

$$
B L_{j}=\frac{n B_{\cdot j}}{V}=\frac{n i^{t} M}{i^{t} M i}
$$

$$
\mathrm{FL}_{\mathrm{i}}=\frac{\mathrm{nB}}{\mathrm{V} \cdot}=\frac{n M i^{\mathrm{t}}}{\mathrm{iMi} \mathrm{i}^{\mathrm{t}}}
$$

\begin{tabular}{|c|c|c|}
\hline & BL $<$ Promedio (BL) & BL $>$ Promedio (BL) \\
\hline FL $<$ Promedio (FL) & independientes & impulsores \\
\hline FL $>$ Promedio (FL) & base & claves \\
\hline
\end{tabular}

Schintke y Stäglin (1988)

$$
w_{i j}(p)=a_{i j}\left[b_{i j} p+100\left(b_{i j} / x_{i j}\right) x_{j}\right]
$$

Donde:

p : representa el porcentaje máximo de variación que se provocará sobre la producción. 
Multiplicadores de Producto (MPM) y Encadenamientos (BL y FL).

\begin{tabular}{|c|c|c|c|c|c|c|c|c|c|c|}
\hline & \multirow{2}{*}{ ACTIVIDAD } & \multicolumn{3}{|c|}{ CHILE } & \multicolumn{3}{|c|}{ PUNTA ARENAS } & \multicolumn{3}{|c|}{ ARICA } \\
\hline & & MPM & $\mathrm{BL}$ & FL & MPM & $\mathrm{BL}$ & FL & MPM & $\mathrm{BL}$ & FL \\
\hline s1 & Productos Agrícolas & 1,72 & 0,97 & 1,11 & 2,93 & 1,36 & 0,49 & 1,60 & 1,17 & 1,01 \\
\hline s2 & Frutas & 1,61 & 0,90 & 0.71 & 2,75 & 1,27 & 0,48 & 1,37 & 1,00 & 0,78 \\
\hline s3 & Ganado; productos pecuarios y carne & 2,06 & 1,16 & 1,25 & 2,81 & 1,30 & 0,76 & 2,02 & 1,47 & 1,31 \\
\hline s4 & Productos silvícolas; Maderas y Papel & 1,83 & 1,03 & 1,10 & 1,89 & 0,88 & 0,51 & 1,57 & 1,15 & 0,78 \\
\hline s5 & $\begin{array}{l}\text { Pescados, Mariscos y P. del Mar } \\
\text { Industrializados }\end{array}$ & 2,45 & 1,37 & 0,97 & 2,21 & 1,03 & 0,65 & 1,14 & 0,83 & 0,92 \\
\hline s6 & $\begin{array}{l}\text { Petróleo crudo y combustibles y } \\
\text { lubricantes }\end{array}$ & 1,47 & 0,83 & 0,61 & 2,44 & 1,13 & 1,16 & -- & -- & -- \\
\hline s7 & Cobre & 1,56 & 0,88 & 0,91 & -- & -- & -- & 1,01 & 0,74 & 0,74 \\
\hline s8 & Otros minerales & 1,63 & 0,91 & 0,81 & 2,39 & 1,11 & 0,83 & 1,02 & 0,74 & 0,74 \\
\hline s9 & Conservas de frutas y vegetales & 2,68 & 1,50 & 0,91 & -- & -- & -- & 1,51 & 1,10 & 0,79 \\
\hline s10 & Aceites y grasas & 1,68 & 0,94 & 0,61 & -- & -- & -- & -- & -- & -- \\
\hline s11 & Productos lácteos & 2,22 & 1,25 & 0,65 & -- & -- & -- & 1,28 & 0,94 & 0,73 \\
\hline s12 & $\begin{array}{l}\text { Productos de molinería, pan, fideos y } \\
\text { pastas }\end{array}$ & 1,95 & 1,09 & 0,76 & 2,53 & 1,17 & 0,48 & 1,57 & 1,15 & 0,74 \\
\hline s13 & Otros productos alimenticios & 1,80 & 1,01 & 0,62 & 2,15 & 1,00 & 0,47 & -- & -- & -- \\
\hline s14 & Alimentos para animales & 2,13 & 1,20 & 1,16 & -- & -- & -- & -- & -- & -- \\
\hline s15 & $\begin{array}{l}\text { Licores; cervezas; bebidas analcohólicas } \\
\text { v vinos }\end{array}$ & 1,98 & 1,11 & 0,69 & 2,63 & 1,22 & 0,57 & 1,47 & 1,07 & 0,74 \\
\hline s16 & Productos del tabaco & 1,84 & 1,04 & 0,61 & -- & -- & -- & -- & -- & -- \\
\hline s17 & $\begin{array}{l}\text { Productos textiles, prendas de vestir, } \\
\text { cuero v calzado }\end{array}$ & 1,81 & 1,02 & 0,65 & 2,65 & 1,23 & 0,53 & 1,41 & 1,03 & 0,77 \\
\hline s18 & Impresos y grabaciones & 1,91 & 1,07 & 1,07 & 2,11 & 0,98 & 0,47 & 1,28 & 0,94 & 0,73 \\
\hline s19 & $\begin{array}{l}\text { Productos químicos, de caucho y de } \\
\text { plástico }\end{array}$ & 1,45 & 0,81 & 1,84 & 2,83 & 1,31 & 9,92 & 1,41 & 1,03 & 0,95 \\
\hline s20 & $\begin{array}{l}\text { Vidrio, P. de vidrio, y P. de Minerales No } \\
\text { Metálicos }\end{array}$ & 2,07 & 1,16 & 0,77 & 1,94 & 0,90 & 0,47 & 1,46 & 1,07 & 0,74 \\
\hline s21 & $\begin{array}{l}\text { Productos básicos de hierro y acero y P. } \\
\text { metálicos }\end{array}$ & 1,77 & 0,99 & 1,02 & 2,52 & 1,17 & 0,47 & 1,26 & 0,92 & 1,08 \\
\hline s22 & $\begin{array}{l}\text { Maquinaria y equipo eléctrico y no } \\
\text { eléctrico }\end{array}$ & 1,64 & 0,92 & 0,81 & 1,87 & 0,87 & 0,48 & 1,52 & 1,11 & 0,78 \\
\hline s23 & Muebles & 2,20 & 1,23 & 0,74 & 1,83 & 0,85 & 0,47 & 1,46 & 1,07 & 0,73 \\
\hline s24 & Otros productos manufactureros & 2,04 & 1,15 & 0,58 & -- & -- & -- & 1,50 & 1,10 & 0,73 \\
\hline s25 & Electricidad & 2,20 & 1,24 & 2,22 & 1,75 & 0,81 & 0,65 & 1,08 & 0,79 & 0,86 \\
\hline s26 & Gas y Agua & 1,52 & 0,85 & 0,64 & 2,17 & 1,01 & 0,53 & 1,07 & 0,78 & 0,79 \\
\hline s27 & Productos de la Construcción & 1,75 & 0,98 & 0,86 & 2,35 & 1,09 & 0,98 & 1,06 & 0,77 & 0,96 \\
\hline s28 & Servicios comerciales & 1,79 & 1,01 & 2,35 & 2,32 & 1,08 & 1,66 & 1,11 & 0,81 & 3,15 \\
\hline s29 & Servicios de hotelería y de restaurantes & 1,98 & 1,11 & 0,66 & 2,29 & 1,06 & 0,54 & 1,13 & 0,82 & 0,82 \\
\hline s30 & Servicios de transporte terrestre & 1,64 & 0,92 & 1,49 & 2,16 & 1,00 & 1,40 & 1,14 & 0,83 & 1,08 \\
\hline s31 & Servicios de transporte marítimo y aéreo & 1,34 & 0,75 & 0,72 & 2,56 & 1,19 & 0,80 & 1,24 & 0,90 & 0,84 \\
\hline s32 & Servicios conexos de transporte & 1,61 & 0,90 & 0,87 & 2,05 & 0,95 & 0,86 & 1,16 & 0,85 & 0,91 \\
\hline s33 & Servicios de comunicaciones & 1,99 & 1,12 & 1,19 & 1,95 & 0,91 & 0,92 & 1,15 & 0,84 & 0,94 \\
\hline s34 & Servicios financieros y de seguros & 1,41 & 0,79 & 1,39 & 1,80 & 0,83 & 0,67 & 1,10 & 0,80 & 0,91 \\
\hline s35 & Servicios empresariales & 1,48 & 0,83 & 3,03 & 2,04 & 0,94 & 1,43 & 1,12 & 0,82 & 1,23 \\
\hline s36 & $\begin{array}{l}\text { Servicios inmobiliarios y de propiedad de } \\
\text { vivienda }\end{array}$ & 1,38 & 0,77 & 1,05 & 1,63 & 0,75 & 0,74 & 1,05 & 0,76 & 0,89 \\
\hline s37 & Servicios de administración pública & 1,38 & 0,78 & 0,61 & 1,60 & 0,74 & 1,31 & 1,12 & 0,82 & 0,96 \\
\hline s38 & Servicio de educación pública y privada & 1,29 & 0,72 & 0,58 & 1,47 & 0,68 & 0,60 & 1,08 & 0,79 & 0,82 \\
\hline s39 & Servicio de salud pública y privada & 1,52 & 0,85 & 0,62 & 1,82 & 0,84 & 0,59 & 1,14 & 0,83 & 0,77 \\
\hline s40 & $\begin{array}{l}\text { Servicios de esparcimiento y otros } \\
\text { servicios }\end{array}$ & 1,47 & 0,83 & 0,76 & 1,81 & 0,84 & 0,61 & 1,16 & 0,85 & 1,02 \\
\hline & Promedio & 1,78 & 1,00 & 1,00 & 2,16 & 1,00 & 1,00 & 1,37 & 1,00 & 1,00 \\
\hline & Máximo & 2,68 & 1,50 & 3,03 & 2,93 & 1,36 & 1,66 & 2,02 & 1,47 & 3,15 \\
\hline & Mínimo & 1,29 & 0,72 & 0,58 & 1,17 & 0,68 & 0,47 & 1,01 & 0,74 & 0,73 \\
\hline
\end{tabular}


Encadenamientos (BL y FL).

\begin{tabular}{|c|c|c|c|c|c|c|c|c|c|c|c|c|c|}
\hline & & & \multicolumn{4}{|c|}{ PUN } & \multicolumn{4}{|c|}{ ARICA } \\
\hline & ACTIVIDAD & $\mathrm{BLi}$ & $\mathrm{FLi}$ & BLz & FLz & $\mathrm{BLi}$ & $\mathrm{FLi}$ & BLz & FLz & $\mathrm{BLi}$ & $\mathrm{FLi}$ & BLz & FLz \\
\hline s1 & Productos Agrícolas & 0.92 & 1.25 & 0.96 & 1.34 & 1,67 & 0,05 & 2,15 & 0,07 & 1.63 & 1.02 & 2.37 & 1.28 \\
\hline s2 & rutas & 0.78 & .34 & 0.90 & 0.39 & 1,51 & 0,03 & 1,95 & 0,04 & 0.99 & 0.18 & 1.76 & 0.30 \\
\hline s3 & $\begin{array}{l}\text { Ganado; } \\
\text { pecuarios }\end{array}$ & 136 & 1.56 & 148 & 171 & 1,57 & 0,56 & 1,39 & 0,10 & 275 & 2.14 & 176 & 0.66 \\
\hline s4 & $\begin{array}{l}\text { Product } \\
\text { Madera }\end{array}$ & 106 & 1.23 & 0.83 & 1.02 & 0,77 & 0,08 & 0,96 & 0,07 & 1.55 & 0.17 & 2.67 & 0.20 \\
\hline s5 & $\begin{array}{l}\text { Pesca } \\
\text { P. del }\end{array}$ & 1.85 & 0.94 & 1.88 & 0.83 & 1,05 & 0,34 & 0,95 & 0,04 & 0.37 & 0.72 & 0.29 & 0.91 \\
\hline s6 & $\begin{array}{l}\text { Petróleo y } \\
\text { combustibles y } \\
\text { lubricantes }\end{array}$ & 0,60 & 0,12 & 0,69 & 0,13 & 1,24 & 1,30 & 1,52 & 1,60 & & & & \\
\hline s7 & Cobre & 0.72 & .81 & 0.63 & 0.73 & -- & -- & & -- & 0.04 & 0.02 & 0.04 & 0.00 \\
\hline s8 & Otro & 0.80 & 0.56 & 0.91 & 0.63 & 1,20 & 0,69 & 1,53 & 0,87 & 0.04 & 0.02 & 0.04 & 0.00 \\
\hline s9 & $\begin{array}{l}\text { Conserv } \\
\text { veaetale }\end{array}$ & 2.15 & 0.80 & 2.33 & 0.78 & -- & -- & -- & -- & 1.37 & 0.21 & 2.21 & 0.13 \\
\hline s10 & Aceit & 0.87 & 0.10 & 0.93 & 0.05 & - & -- & -- & -- & & & & \\
\hline s11 & Produc & 1.56 & 0.20 & 1.71 & 0.15 & - & -- & -- & -- & 0.76 & 0.00 & 1.37 & 0.00 \\
\hline s12 & & 1.21 & 0.46 & 1.16 & 0.30 & 1,32 & 0,03 & 1,70 & 0,02 & 1.56 & 0.02 & 2.76 & 0.00 \\
\hline s13 & $\begin{array}{l}\text { Otr } \\
\text { alin }\end{array}$ & 102 & 0.14 & 1.13 & 0.12 & 0,99 & 0,01 & 1,28 & 0,01 & -- & -. & -- & -- \\
\hline s14 & & 145 & 1.36 & 1.61 & 1.50 & -- & -- & -- & -- & -- & -- & -- & -- \\
\hline s15 & & 1.25 & 0.28 & 1.27 & 0.16 & 1,41 & 0,20 & 1,68 & 0,13 & 27 & 0.04 & 2.22 & 0.02 \\
\hline s16 & tabaco & 1.08 & 0.11 & 1.12 & 0.00 & -- & -- & -- & -- & - & & -- & -- \\
\hline s17 & $\begin{array}{l}\text { Pro } \\
\text { vest }\end{array}$ & 1.04 & 0.20 & 1.06 & 0.09 & 1,43 & 0,12 & 1,70 & 0,01 & 1.11 & 0.13 & 1.79 & 0.04 \\
\hline s18 & & 1.16 & 1.15 & 1.14 & 1.13 & 0,96 & 0,01 & 1,24 & 0,01 & 0.76 & 0.00 & 1.36 & 0.00 \\
\hline s19 & $\begin{array}{l}\text { Prod } \\
\text { cauc }\end{array}$ & 0.57 & 2.91 & 0.56 & 3.24 & 1,58 & 17,6 & 0,63 & 21,3 & 1.11 & 0.81 & 1.73 & \\
\hline s20 & $\begin{array}{l}\text { Vidri } \\
\text { Mine } \\
\text { Metá }\end{array}$ & 1.37 & 0.47 & 1.38 & 0.35 & 0,81 & 0,00 & 1,05 & 0,01 & 1.25 & 0.03 & 2.20 & 0.01 \\
\hline s21 & & 0.99 & 1.04 & 0.93 & 0.99 & 1,31 & 0,01 & 1,69 & 0,01 & & 1.31 & 0.93 & \\
\hline s22 & & & 0.56 & 0.91 & & 0,75 & 0,03 & 0,96 & 0,04 & & & & 0.20 \\
\hline s23 & & 1.54 & 0.40 & 1.52 & 0.22 & 0,72 & 0,02 & 0,92 & 0,02 & 1.25 & 0.00 & 2.23 & 0.00 \\
\hline s24 & & 1.33 & .05 & & & -- & -- & -- & -- & & & & \\
\hline s25 & & $\begin{array}{l}35 \\
54\end{array}$ & .05 & $\begin{array}{l}.53 \\
.63\end{array}$ & .18 & 0,65 & 0,35 & 0,82 & 0,43 & $\begin{array}{l}.30 \\
.20\end{array}$ & 77 & 0 & $\begin{array}{l}0.00 \\
0.77\end{array}$ \\
\hline s26 & & 0.66 & 0.18 & 0.72 & 0.17 & 1,01 & 0,13 & 1,30 & 0,17 & 0.18 & 0.23 & 0.32 & 0.40 \\
\hline s27 & & 0.96 & 0.68 & 1.09 & 0.78 & 1,17 & 0,96 & 1,50 & 1,23 & 0.17 & 0.84 & 0.29 & 1.50 \\
\hline s28 & & 1.02 & 4.07 & 1.04 & 4.54 & 1,15 & 2,23 & 1,33 & 2,73 & 0.29 & 8.96 & 0.39 & 15.8 \\
\hline s29 & & 1.25 & 0.23 & 1.43 & 0.26 & 1,12 & 0,14 & 1,43 & 0,17 & 0.34 & 0.33 & 0.61 & 058 \\
\hline s30 & & 0.82 & 2.12 & 0.84 & 2.33 & 1,00 & 1,75 & 1,20 & 2,16 & 0.37 & 1.31 & 0.65 & 2.33 \\
\hline s31 & & 0.43 & 0.37 & 0.46 & 0.39 & 1,35 & 0,63 & 1,55 & 0,63 & 0.65 & 0.39 & 0.46 & 0.00 \\
\hline s32 & os de & 0.78 & 0.70 & 0.76 & 0.66 & 0,91 & 0,74 & 1,07 & 0,85 & 0.43 & 0.68 & 0.59 & 1.03 \\
\hline s33 & & 1.27 & 1.43 & 0.80 & 0.98 & 0,83 & 0,85 & 0,98 & 1,01 & 0.40 & 0.77 & 0.57 & 1.23 \\
\hline s34 & $\operatorname{eros} y$ & 0.53 & 1.90 & 0.46 & 2.03 & 0,69 & 0,39 & 0,87 & 0,49 & 0.27 & 0.68 & 0.41 & 1.14 \\
\hline s35 & & 0.61 & 5.63 & 0.46 & 6.23 & 0,90 & 1,79 & 1,08 & 2,23 & 0.33 & 1.84 & 0.52 & 3.21 \\
\hline s36 & tios y de & 0.48 & 1.12 & 0.53 & 1.25 & 0,54 & 0,51 & 0,69 & 0,65 & 0.13 & 0.58 & 0.22 & 1.04 \\
\hline s37 & & 0.49 & 0.11 & 0.56 & 0.12 & 0,52 & 1,58 & 0,66 & 2,03 & 0.33 & 0.84 & 0.59 & 1.50 \\
\hline s38 & & 0.37 & 0.04 & 0.42 & 0.05 & 0,41 & 0,26 & 0,48 & 0,29 & 0.22 & 0.34 & 0.24 & 0.46 \\
\hline s39 & & 0.67 & 0.14 & 0.66 & 0.05 & 0,71 & 0,24 & 0,85 & 0,24 & 0.38 & 0.16 & 0.56 & 0.16 \\
\hline s40 & nto $y$ & 0.60 & 0.44 & 0.63 & 0.44 & 0,70 & 0,28 & 0,89 & 0,35 & 0.44 & 1.07 & 0.63 & 1.76 \\
\hline & Prom & 1.00 & 1.00 & 1.00 & 1.00 & 1.00 & 1.00 & 1.00 & 1.00 & 1.00 & 1.00 & 1.00 & 1.00 \\
\hline & Máximo & 2.15 & 5.63 & 2.33 & 6.23 & 1.67 & 17.6 & 2.15 & 21.3 & 2.75 & 8.96 & 2.76 & 15.8 \\
\hline & Mínimo & 0.37 & 0.04 & 0.42 & 0.00 & 0.41 & 0.00 & 0.48 & 0.01 & 0.04 & 0.00 & 0.00 & 0.00 \\
\hline
\end{tabular}




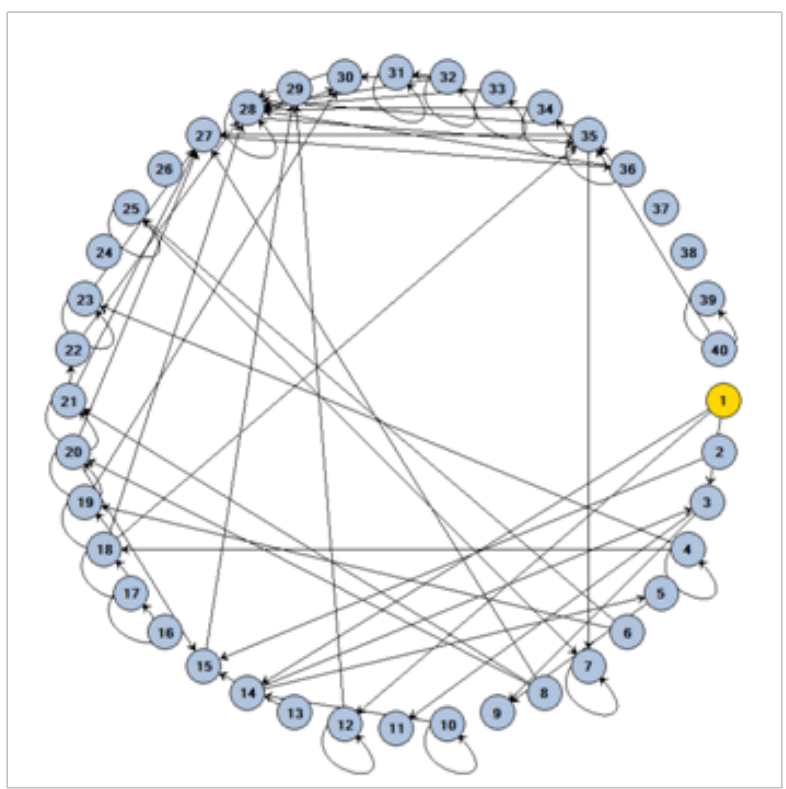

Fig. 12 Campos de Influencia (CdI). Chile 2003.

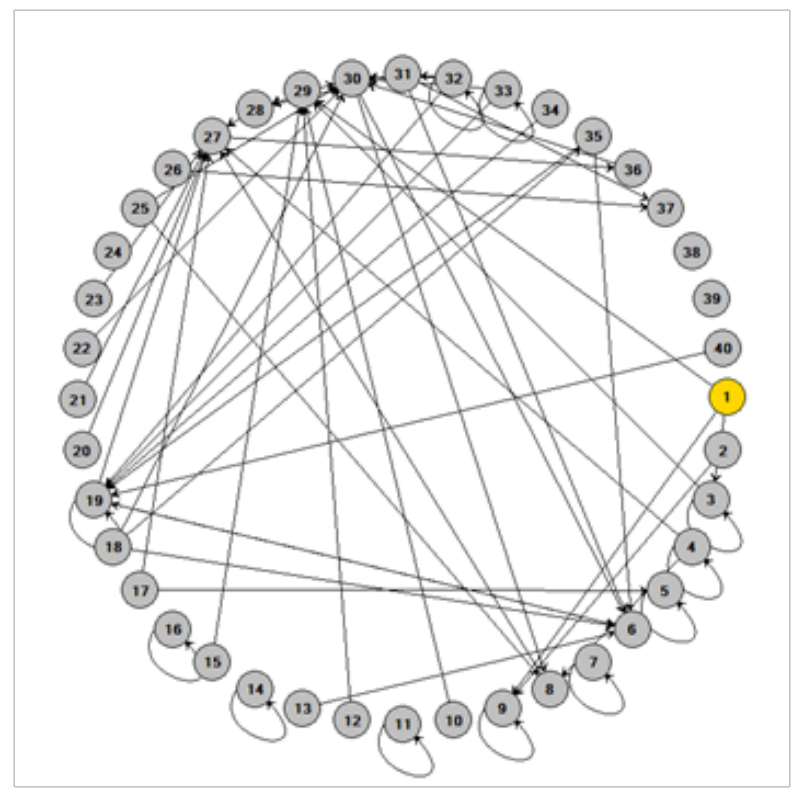

Fig. 13 Campos de Influencia (CdI). Punta Arenas 2003 
P. AROCA \& S. SOZA-AMIGO 